\title{
Acute and Chronic Administrations of Rheum palmatum Reduced the Bioavailability of Phenytoin in Rats: A New Herb-Drug Interaction
}

\author{
Ying-Chang Chi, ${ }^{1}$ Shin-Hun Juang, ${ }^{1}$ Wai Keung Chui, ${ }^{2}$ \\ Yu-Chi Hou, ${ }^{3,4}$ and Pei-Dawn Lee Chao ${ }^{3}$ \\ ${ }^{1}$ Institute of Pharmaceutical Chemistry, China Medical University, Taichung 40402, Taiwan \\ ${ }^{2}$ Department of Pharmacy, Faculty of Science, National University of Singapore, 18 Science Drive 4, Singapore 117543 \\ ${ }^{3}$ School of Pharmacy, China Medical University, Taichung 40402, Taiwan \\ ${ }^{4}$ Department of Medical Research, China Medical University Hospital, Taichung 40402, Taiwan
}

Correspondence should be addressed to Yu-Chi Hou, hou5133@gmail.com and Pei-Dawn Lee Chao, p22340069@gmail.com

Received 16 March 2012; Revised 23 April 2012; Accepted 27 April 2012

Academic Editor: Paul Siu-Po Ip

Copyright (C) 2012 Ying-Chang Chi et al. This is an open access article distributed under the Creative Commons Attribution License, which permits unrestricted use, distribution, and reproduction in any medium, provided the original work is properly cited.

The rhizome of Rheum palmatum (RP) is a commonly used herb in clinical Chinese medicine. Phenytoin (PHT) is an antiepileptic with narrow therapeutic window. This study investigated the acute and chronic effects of RP on the pharmacokinetics of PHT in rat. Rats were orally administered with PHT $(200 \mathrm{mg} / \mathrm{kg})$ with and without RP decoction (single dose and seven doses of $2 \mathrm{~g} / \mathrm{kg}$ ) in a crossover design. The serum concentrations of PHT, PHT glucuronide (PHT-G), 4-hydroxyphenytoin (HPPH), and HPPH glucuronide (HPPH-G) were determined by HPLC method. Cell line models were used to identify the underlying mechanisms. The results showed that coadministration of single dose or multiple doses of RP significantly decreased the $C_{\max }$ and $\mathrm{AUC}_{0-t}$ as well as the $K_{10}$ of PHT, PHT-G, HPPH, and HPPH-G. Cell line studies revealed that RP significantly induced the P-gp-mediated efflux of PHT and inhibited the MRP-2-medicated transport of PHT and HPPH. In conclusion, acute and chronic coadministrations of RP markedly decreased the oral bioavailability of PHT via activation of P-gp, although the MRP-2-mediated excretion of PHT was inhibited. It is recommended that caution should be exercised during concurrent use of RP and PHT.

\section{Introduction}

The rhizome of Rheum palmatum (RP, Dahuang) is one of the important herbs widely used in China, Russia, and Arabia [1]. The major constituents of RP include a variety of anthraquinones such as aloe-emodin, rhein, emodin, chrysophanol and physcion $[2,3]$, which have been reported to show various beneficial effects, including neuroprotective, antioxidant, anti-inflammatory, and anticancer activities [48]. Recent pharmacokinetic studies of RP have revealed that the anthraquinones were all predominantly present as glucuronides and sulfates in the blood $[3,8]$ and they are also putative substrates of multidrug resistance proteins (MRPs), namely, the anion transporters.
Phenytoin (PHT), a widely used antiepileptic with narrow therapeutic window, follows nonlinear pharmacokinetics, and thus therapeutic drug monitoring is usually recommended during its use [9]. The adverse reactions of PHT include drowsiness, dysarthria, tremor, and cognitive difficulties $[10,11]$. PHT has been reported as a substrate of P-glycoprotein (P-gp) and MRP 2, whose expressions determined the PHT level in brain $[12,13]$. PHT is metabolized to its main metabolite 4-hydroxyphenytoin (HPPH) by cytochrome P450 (CYP) 2C9 and to a minor extent by CYP 2C19 [14, 15]. Both PHT and HPPH are metabolized by glucuronidation to form PHT glucuronide (PHT-G) and HPPH glucuronide (HPPH-G), respectively $[16,17]$. 
Based on our understanding on the metabolic fates and pharmacokinetics of PHT and anthraquinones in RP, we hypothesized that the metabolites of anthraquinones might compete with PHT, HPPH, PHT-G, or HPPH-G for anion transporters such as MRP 2. Patients suffering from epilepsy are generally dependent on life-long antiepileptic treatment. On other hand, using RP for constipation is an excellent home remedy in oriental countries. Therefore, it is probable that epileptic patients combined the use of PHT and RP. As such coadministration of RP and PHT may give rise to adverse effects, therefore, this study was set up to investigate the acute and chronic effects of coadministration of RP on the pharmacokinetics of PHT in rats. In addition, cell line models would be used to explore the underlying mechanism of this herb-drug interaction.

\section{Materials and Methods}

2.1. Chemicals and Reagents. PHT (purity 99\%), HPPH (purity 98\%), aloe-emodin (purity 95\%), rhein (purity 95\%), emodin (purity 95\%), chrysophanol (purity 98\%), physcion (purity 98\%), verapamil (purity 99\%), indomethacin (purity 98\%), propylparaben (purity 99\%), 2methylanthraquinone (purity 95\%), rhodamine 123 (purity 99\%), and 3-(4,5-dimethylthiazol-2-yl)-2,5-diphenyl tetrazolium bromide (MTT) were purchased from Sigma Chemical Co. (St. Louis, MO, USA). L(+)-Ascorbic acid was obtained from Riedel-de Haën Laborchemikalien $\mathrm{GmbH}$ \& Co. KG (Seelze, Germany). Fetal bovine serum was supplied by Biological Industries Ltd., Kibbutz Beit Haemek, Israel). L-Glutamine, penicillin, streptomycin, nonessential amino acid, trypsin-EDTA, and Hank's balanced salt solution (HBSS) were purchased from Invitrogen Inc. (Carlsbad, CA, USA). Total protein assay kit was purchased from Bio-Rad Inc. (Mississauga, ON, Canada). Other reagents were HPLC grade or analytical grade. Milli-Q plus water (Millipore, Bedford, MA, USA) was used throughout this study.

2.2. Preparation and Characterization of RP Decoction. The crude drug of RP was purchased from a Chinese drugstore in Taichung, Taiwan. The origin was identified by Dr. YuChi Ho via microscopic examination. A voucher specimen (CMU-P-1905-9) was deposited in the College of Pharmacy, China Medical University. Water (5 L) was added to $250 \mathrm{~g}$ of the crude drug. After maceration for $1 \mathrm{~h}$, the mixture was heated to boiling and gentle heating was continued for about $2 \mathrm{~h}$ until the volume was reduced to less than 2.5 L. The mixture was filtered while hot and the filtrate was concentrated further by gentle boiling until the volume was reduced to below $500 \mathrm{~mL}$, after which sufficient water was added to make $500 \mathrm{~mL}(0.5 \mathrm{~g} / \mathrm{mL}$ of $\mathrm{RP})$. The resultant concentrate was divided into aliquots of $40 \mathrm{~mL}$ and stored at $-20^{\circ} \mathrm{C}$ for later use.

The concentrations of aloe-emodin, rhein, emodin, chrysophanol, and physcion in RP decoction and its hydrolysate were determined by an HPLC method. For acid hydrolysis, a portion of the decoction $(1.0 \mathrm{~mL})$ was added $1.2 \mathrm{~N} \mathrm{HCl}(1 \mathrm{~mL}), 25 \mathrm{mg}$ of ascorbic acid and incubated at $80^{\circ} \mathrm{C}$ for $30 \mathrm{~min}$. This method was determined by a previous preliminary study. The mixture was then added with $4.0 \mathrm{~mL}$ of methanol. After vortexing and centrifugation, the supernatant $(100 \mu \mathrm{L})$ was mixed with $100 \mu \mathrm{L}$ of internal standard in the form of 2-methylanthraquinone solution $(50 \mu \mathrm{g} / \mathrm{mL}$ in methanol) and $20 \mu \mathrm{L}$ of this solution was subjected to HPLC analysis. A gradient elution was carried out using a mobile phase consisting of $0.1 \%$ phosphoric acid (A) and acetonitrile (B) that were mixed in the following program: $A / B=50 / 50$ (0-10 $\mathrm{min}), 15 / 85$ (15-22 $\mathrm{min}), 50 / 50$ (27-30 min). The detection wavelength was set at $280 \mathrm{~nm}$ and the flow rate was maintained at $1.0 \mathrm{~mL} / \mathrm{min}$. The concentration of anthraquinone glycoside was estimated from the difference of aglycone concentrations between RP decoction and its acid hydrolysate.

2.3. Animals and Drug Administration. Male SpragueDawley rats were supplied by National Laboratory Animal Center (Taipei, Taiwan) and kept in the animal center of the China Medical University (Taichung, Taiwan). The animal protocol was approved by the Institutional Animal Care and Use Committee of the China Medical University. The animal study was conducted with adherence to "The Guidebook for the Care and Use of Laboratory Animals" published by the Chinese Society of Animal Science, Taiwan. The rats (300-400 g) were fasted for $12 \mathrm{~h}$ before drug administration. PHT was dissolved in dil. $\mathrm{NaOH}$ to afford a solution of $20.0 \mathrm{mg} / \mathrm{mL}$ [18]. PHT was given via gastric gavage to six rats at $200.0 \mathrm{mg} / \mathrm{kg}$ with and without a concomitant oral dose of RP decoction (single dose and seven doses of $2 \mathrm{~g} / \mathrm{kg}$ ) in a crossover design. The RP decoction was administered right before PHT.

2.4. Blood Collection. Blood samples $(0.5 \mathrm{~mL})$ were withdrawn via cardiac puncture at time points of $0,15,30$, $60,120,240,480$, and $720 \mathrm{~min}$ after oral administration of PHT. The blood samples were collected in microtubes and centrifuged at 10,000 $\mathrm{g}$ for $15 \mathrm{~min}$ to obtain the serum, which was stored at $-70^{\circ} \mathrm{C}$ before analysis.

2.5. Determination of PHT and Its Metabolites in Serum. For the determination of free forms of PHT and $\mathrm{HPPH}$, $100 \mu \mathrm{L}$ of serum sample was mixed with $50 \mu \mathrm{L}$ of $\mathrm{pH} 5$ acetate buffer and $50 \mu \mathrm{L}$ of ascorbic acid $(100 \mathrm{mg} / \mathrm{mL})$. The mixture was extracted with $200 \mu \mathrm{L}$ of ethyl acetate (containing propylparaben as internal standard, $5 \mu \mathrm{g} / \mathrm{mL}$ ). The ethyl acetate layer was evaporated under $\mathrm{N}_{2}$ to dryness and reconstituted with an appropriate volume of acetonitrile and then subjected to HPLC analysis.

For the assay of PHT-G and HPPH-G in serum, indirect determination was carried out through hydrolysis with $\beta$ glucuronidase in pH 5 acetate buffer. Serum sample $(100 \mu \mathrm{L})$ was mixed with $50 \mu \mathrm{L}$ of $\beta$-glucuronidase (1000 units $/ \mathrm{mL}$ ) and $50 \mu \mathrm{L}$ of ascorbic acid $(100 \mathrm{mg} / \mathrm{mL})$ and incubated at $37^{\circ} \mathrm{C}$ for $60 \mathrm{~min}$ under anaerobic condition. After hydrolysis, the analytical procedures followed that for the assay of the free forms as described above. 
2.6. Cell Lines and Cell Culture. LS 180, the human colon adenocarcinoma cell line, was obtained from the Food Industry Research and Development Institute (Hsinchu, Taiwan). The nontransfected and MRP-2-overexpressing MDCK II cell lines were kindly provided by Professor Piet Borst (Dutch Cancer Institute, Amsterdam, The Netherlands). The cell lines were cultured in DMEM medium supplemented with $10 \%$ fetal bovine serum, $0.1 \mathrm{mM}$ nonessential amino acid (LS 180 cell line only), 100 units $/ \mathrm{mL}$ of penicillin, $100 \mu \mathrm{g} / \mathrm{mL}$ of streptomycin, and $292 \mu \mathrm{g} / \mathrm{mL}$ of glutamine. Cells were grown at $37^{\circ} \mathrm{C}$ in a humidified incubator containing $5 \% \mathrm{CO}_{2}$. The medium was changed every other day, and the cells were subcultured until 80-90\% confluency was reached.

2.7. Cytotoxicity Assay. Verapamil hydrochloride was dissolved in water. PHT and HPPH were dissolved in dil. $\mathrm{NaOH}$ ( $\mathrm{pH}$ 9.0). Indomethacin (Indo) was dissolved in $\mathrm{MeOH}$ and the final concentration of $\mathrm{MeOH}$ in medium was below $0.1 \%(\mathrm{v} / \mathrm{v})$. LS 180 , MDCK II, and MDCK IIMRP 2 cells $\left(1 \times 10^{5}\right.$ cells/well $)$ were seeded into 96-well plates. After overnight incubation, the test agents were added into the wells and incubated for $72 \mathrm{~h}$ and then $15 \mu \mathrm{L}$ of MTT $(5 \mathrm{mg} / \mathrm{mL})$ was added into each well and incubated for additional $4 \mathrm{~h}$. During this period, MTT was reduced to formazan crystal by live cells. An acidic SDS (10\%) solution was added to solubilize the purple crystal formed at the end of incubation and the optical density was measured at $570 \mathrm{~nm}$ by a microplate reader (Nunc, Denmark).

2.8. Transport Study of PHT in LS 180. LS 180 cells (passage 50 to 60 ) were seeded on 12-well plates at a density of $5 \times 10^{5}$ cells/well. Before the experiment, the medium was removed and the cells were quickly rinsed with ice-cold HBSS transport buffer consisting of HEPES ( $10 \mathrm{mM}$, pH 7.4.). PHT $(10 \mu \mathrm{M})$ was coincubated with and without RP $(2.0,1.0$ and $0.5 \mathrm{mg} / \mathrm{mL})$ and verapamil $(100 \mu \mathrm{M})$ with LS 180 for $90 \mathrm{~min}$. After incubation, the cells were rapidly washed twice with ice-cold HBSS buffer and lysed with $200 \mu \mathrm{L}$ of $0.1 \%$ Triton $\mathrm{X}-100$ for $30 \mathrm{~min}$.

Total protein content in the lysate $(5 \mu \mathrm{L})$ was determined by Bradford method [19], and bovine serum albumin was used as the standard. The protein contents in each well were used for data correction.

2.9. Preparation and Characterization of Serum Metabolites of $R P(R P M s)$. In order to mimic the molecules interacting with MRP 2 in the kidney, RPMs was prepared using rats. After overnight fasting, rats were given RP decoction at $2 \mathrm{~g} / \mathrm{kg}$. Blood was collected at $30 \mathrm{~min}$ after dosing. The serum was added with 3 -fold methanol. After vortex and centrifugation at $10,000 \mathrm{~g}$ for $15 \mathrm{~min}$, the supernatant was dried in a rotatory evaporator under vacuum. To the residue, an appropriate volume of water was added to afford a solution with a 10 -fold serum concentration, which was divided into aliquots and stored at $-80^{\circ} \mathrm{C}$ for later use. The procedures for the characterization of RPMs followed that of a previous study $[2,3]$. Briefly, $100 \mu \mathrm{L}$ of serum sample were mixed with $50 \mu \mathrm{L}$ of sulfatase solution (containing
1000 units $/ \mathrm{mL}$ of sulfatase and $35,600 \mathrm{units} / \mathrm{mL}$ of $\beta$ glucuronidase) and $50 \mu \mathrm{L}$ of ascorbic acid $(100 \mathrm{mg} / \mathrm{mL})$ and incubated at $37^{\circ} \mathrm{C}$ for $10 \mathrm{~min}$ under anaerobic condition. After hydrolysis, the serum was acidified with $50 \mu \mathrm{L}$ of $0.1 \mathrm{~N}$ $\mathrm{HCl}$ and extracted with $250 \mu \mathrm{L}$ of ethyl acetate (containing 2 -methylanthraquinone as internal standard, $1 \mu \mathrm{g} / \mathrm{mL}$ ). The ethyl acetate layer was evaporated under $\mathrm{N}_{2}$ to dryness and reconstituted with an appropriate volume of methanol prior to HPLC analysis. In addition, the serum of rats given water only was collected to prepare the blank control. The blank serum was processed as described above and diluted to various folds of serum concentration for the comparison with correspondent concentration of RPMs.

2.10. Transport Study of PHT and HPPH in MDCK II and MDCK II-MRP 2. MDCK II and MDCK II-MRP 2 cells within 10 passages were seeded on 12-well plates at a density of $3 \times 10^{5}$ cells/well. Before experiment, the medium was removed and the cells were quickly rinsed with ice-cold HBSS transport buffer. To determine whether PHT and HPPH are substrates of MRP 2, PHT $(10 \mu \mathrm{M}), \mathrm{HPPH}(10 \mu \mathrm{M})$ and Indo $(50,100$ and $200 \mu \mathrm{M}$, as a positive control of MRP 2 inhibitor) were incubated with MDCK II and MDCK IIMRP 2 for 60 min.

In another study, RPMs and Indo $(100 \mu \mathrm{M})$ in HBSS were preincubated with MDCK II-MRP 2 for $30 \mathrm{~min}$. The supernatants were removed and cells were washed three times with ice-cold PBS. Then, PHT $(10 \mu \mathrm{M})$ and HPPH $(10 \mu \mathrm{M})$ were coincubated with and without RPMs (1.0-, 0.5-, and 0.25 -fold of serum concentrations) and Indo $(200 \mu \mathrm{M})$ with MDCK II-MRP 2 for another 30 min. After incubation, the cells were rapidly washed twice with ice-cold HBSS buffer and lysed with $200 \mu \mathrm{L}$ of $0.1 \%$ Triton X-100 for $30 \mathrm{~min}$.

Total protein content in the lysate $(5 \mu \mathrm{L})$ was determined by Bradford method [19], and bovine serum albumin was used as the standard. The protein contents in each well were used for data correction.

2.11. Determination of PHT and HPPH Concentrations in Cell Lysate. For the assay of PHT and HPPH, $200 \mu \mathrm{L}$ of cell lysate was extracted with $200 \mu \mathrm{L}$ of ethyl acetate (containing propylparaben as internal standard, $5 \mu \mathrm{g} / \mathrm{mL}$ ). The ethyl acetate layer was evaporated under $\mathrm{N}_{2}$ to dryness and reconstituted with an appropriate volume of acetonitrile, then subjected to HPLC analysis.

2.12. Assay and Method Validation of PHT and HPPH in Serum and Cell Lysate. An HPLC method using a mixture of methanol and $0.05 \%$ phosphoric acid $(48: 52)$ as mobile phase was developed and validated for the assay of PHT and HPPH in serum and cell lysate. The detection wavelength was set at $214 \mathrm{~nm}$ and the flow rate was $1.0 \mathrm{~mL} / \mathrm{min}$. The calibration ranges of PHT and HPPH were $0.2-50.0 \mu \mathrm{g} / \mathrm{mL}$ for serum and cell lysate. The precision and accuracy of the analytical method was evaluated by intraday and interday analysis of triplicate standards within one day and over a period of three days. Recoveries from serum were calculated based on the detected concentrations in serum compared 


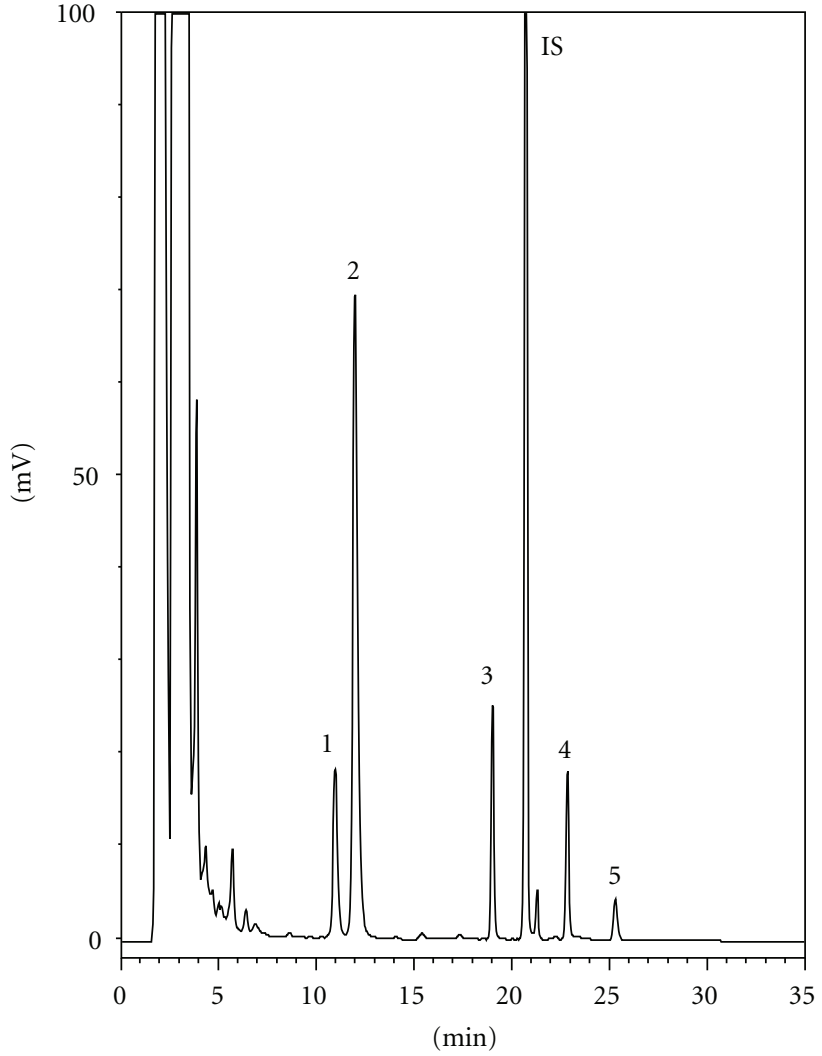

(a)

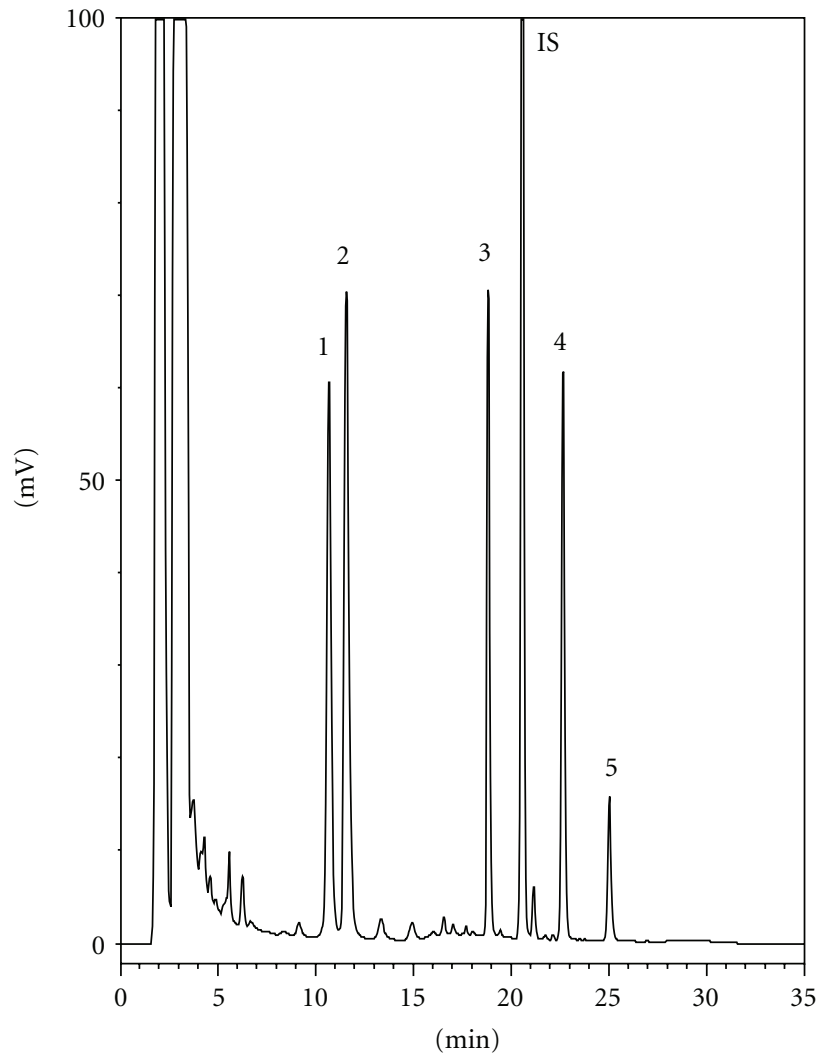

(b)

FIGURE 1: HPLC chromatograms of RP decoction before (a) and after (b) acid hydrolysis. 1: aloe-emodin, 2: rhein, 3: emodin, 4: chrysophanol, 5: physcion, IS: 2-methylanthraquinone.

with those in water. The mixture was extracted with $200 \mu \mathrm{L}$ of ethyl acetate containing $5 \mu \mathrm{g} / \mathrm{mL}$ of propylparaben as internal standard. The ethyl acetate layer was evaporated under $\mathrm{N}_{2}$ to dryness and reconstituted with an appropriate volume of acetonitrile and then subjected to HPLC analysis. LOQ (Limit of Quantitation) represents the lowest concentration of analyte that can be determined with acceptable precision and accuracy with coefficients of variation and relative errors below $15 \%$ and 20\%, respectively. LOD (Limit of Detection) represents the lowest concentration of analyte that can be detected with $\mathrm{S} / \mathrm{N}>3$.

2.13. Data Analysis. The areas under the serum concentration-time curves $\left(\mathrm{AUC}_{0-t}\right)$ of PHT, PHT-G, HPPH, and HPPH-G were calculated using noncompartment model (version 1.1, SCI software, Statistical Consulting, Inc., Apex, NC, USA). The peak serum concentrations $\left(C_{\max }\right)$ were from experimental data. One-way ANOVA with Scheffe's test was used for statistical comparison taking $P<0.05$ as significant.

\section{Results}

3.1. Characterization of RP Decoction. Figure 1 shows the chromatograms of the RP decoction before and after acid hydrolysis. Quantitation results showed that the concentrations of aloe-emodin, rhein, emodin, chrysophanol, and physcion were $0.9,2.0,0.5,0.4$, and $0.1 \mathrm{nmol} / \mathrm{mL}$ in the decoction and $2.3,3.8,2.0,1.8$, and $0.7 \mathrm{nmol} / \mathrm{mL}$ in the acid hydrolysate of decoction, respectively. Accordingly, a dose of $2 \mathrm{~g} / 4 \mathrm{~mL} / \mathrm{kg} \mathrm{RP}$ was found to contain 9.2, 15.2, 8.0, 7.2 , and $2.8 \mathrm{nmol} / \mathrm{kg}$ of aloe emodin, rhein, emodin, and chrysophanol with the relevant glycosides, respectively.

3.2. Assay of PHT and HPPH in Serum and Method Validation. In serum assay, the calibration curves of PHT and $\mathrm{HPPH}$ showed good linearity in the concentration range of $0.2-50 \mu \mathrm{g} / \mathrm{mL}$. The precision evaluation revealed that all coefficients of variation were below $15 \%$ and the accuracy analysis showed that the relative errors to the true concentrations were below 10\%. The recoveries of PHT and HPPH from serum were $95.1-100.8 \%$ and $94.1-99.0 \%$, respectively. The LLOQ of PHT and $\mathrm{HPPH}$ was $0.4 \mu \mathrm{g} / \mathrm{mL}$ and the LOD was 0.01 and $0.02 \mu \mathrm{g} / \mathrm{mL}$, respectively.

3.3. Effect of RP on PHT Pharmacokinetics in Rats. Figure 2 depicts the mean serum concentration-time profiles of PHT, PHT-G, HPPH, and HPPH-G after oral administration of PHT alone and oral coadministration with single dose and pretreatment with seven doses of $2 \mathrm{~g} / \mathrm{kg}$ of RP. The pharmacokinetic parameters of PHT, PHT-G, HPPH, and HPPH-G are listed in Table 1. Coadministration of RP with single dose of $2 \mathrm{~g} / \mathrm{kg}$ significantly decreased the $C_{\max }$ of 


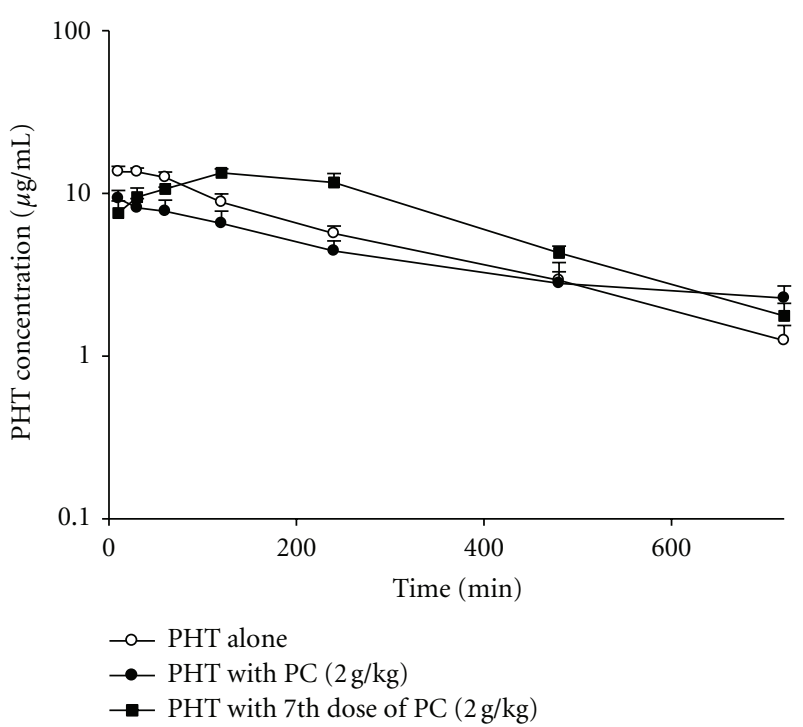

(a)

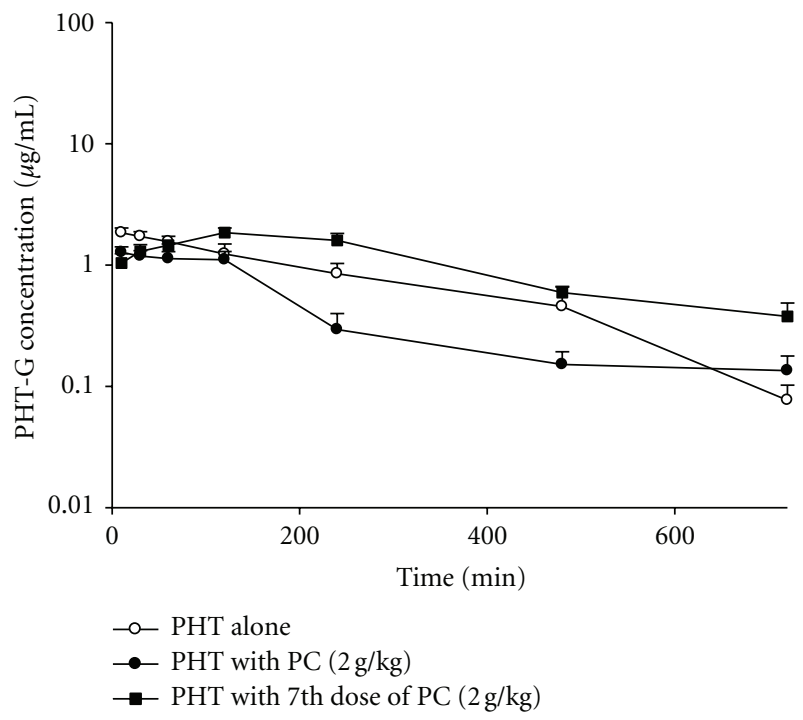

(c)

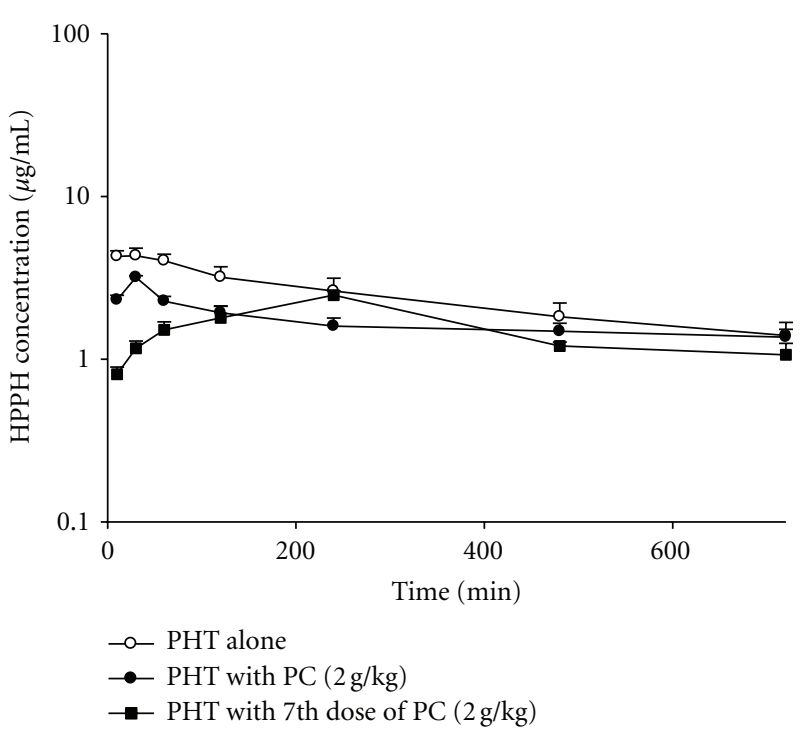

(b)

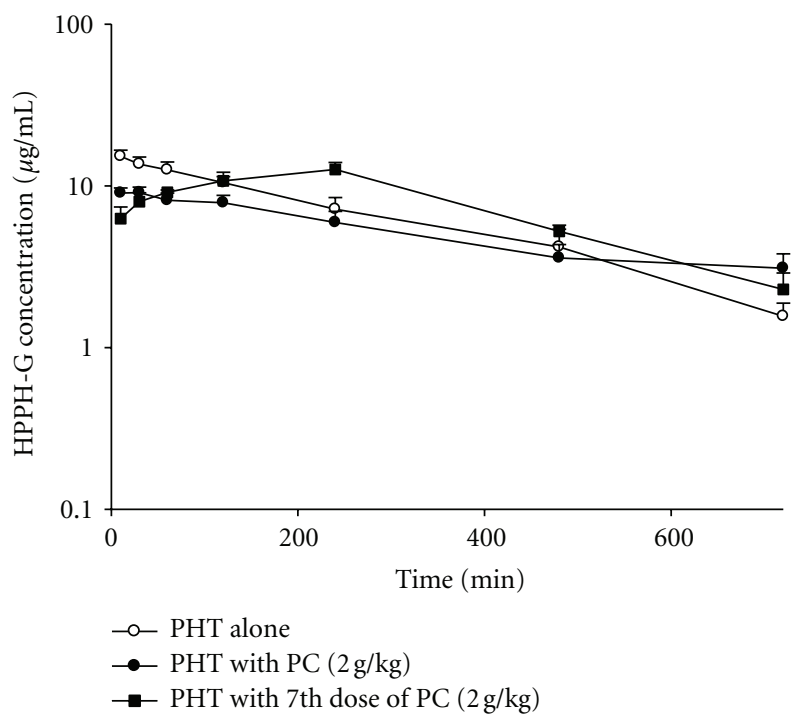

(d)

Figure 2: Mean ( \pm S.E.) serum concentration-time profiles of PHT (a), HPPH (b), PHT-G (c), and HPPH-G (d) after oral administration of PHT alone $(200 \mathrm{mg} / \mathrm{kg})(\circ)$, coadministration with single dose $(\bullet)$, and 7 th dose of $2 \mathrm{~g} / \mathrm{kg}(\mathbf{\square})$ of RP decoction in six rats.

PHT, PHT-G, HPPH and HPPH-G by 51.0, 51.7, 43.9, and $42.5 \%$ and reduced the $\mathrm{AUC}_{0-720}$ by $36.9,51.7,30.3$, and $22.8 \%$, respectively. Pretreatment with seven doses of RP significantly decreased the $C_{\max }$ of PHT, PHT-G, HPPH, and HPPH-G by $53.1 \%, 65.1 \%, 46.3 \%$, and $44.3 \%$ and reduced their $\mathrm{AUC}_{0-720}$ by $51.9 \%, 64.8 \%, 37.5 \%$ and $30.6 \%$, respectively. In addition, the $K_{10}$ of PHT, PHT-G HPPH, and HPPH-G were significantly decreased upon acute and chronic coadministrations of RP.

3.4. Cytotoxicity Assay. More than $90 \%$ of cells were viable at the concentrations of PHT, HPPH and RP up to $10 \mu \mathrm{M}$, $10 \mu \mathrm{M}$, and $2 \mathrm{mg} / \mathrm{mL}$ in LS 180 , respectively. In addition, PHT, HPPH, and RPM at $10 \mu \mathrm{M}, 10 \mu \mathrm{M}$, and 1.0-fold serum concentration, respectively, did not possess any noticeable cytotoxicity against MDCK II and MDCK II-MRP 2.

3.5. Transport Studies of PHT and HPPH. The effects of RP and verapamil on the intracellular accumulation of PHT in LS 180 cells are shown in Figure 3. RP at 2.0, 1.0 and $0.5 \mathrm{mg} / \mathrm{mL}$ significantly decreased the intracellular accumulation of PHT by $43.6,37.3$, and $22.9 \%$, indicating $\mathrm{RP}$ concentration-dependently activated the efflux function of P-gp.

Figure 4 shows the differences of intracellular accumulation of PHT and HPPH in presence and absence of Indo in MDCK II and MDCKII-MRP 2. The results showed that the accumulations of PHT and HPPH in MDCKII 
TAble 1: Pharmacokinetic parameters of PHT, PHT-G, HPPH, and HPPH-G in six rats receiving oral PHT (200 mg/kg) alone and coadministration with single dose and seven doses of RP decoction $(2 \mathrm{~g} / \mathrm{kg})$.

\begin{tabular}{|c|c|c|c|}
\hline \multirow{2}{*}{ Parameters } & \multicolumn{3}{|c|}{ Treatments } \\
\hline & PHT alone & $\begin{array}{c}\mathrm{PHT}+\mathrm{RP} \\
(2 \mathrm{~g} / \mathrm{kg})\end{array}$ & $\begin{array}{c}\text { PHT + RP } \\
\text { (7th dose of } 2 \mathrm{~g} / \mathrm{kg})\end{array}$ \\
\hline \multicolumn{4}{|l|}{ PHT } \\
\hline$C_{\max }$ & $15.7 \pm 0.7^{\mathrm{a}}$ & $\begin{array}{c}7.5 \pm 0.6^{\mathrm{b}} \\
(-51.0 \pm 5.1 \%)\end{array}$ & $\begin{array}{c}7.3 \pm 0.6^{\mathrm{b}} \\
(-53.1 \pm 3.7 \%)\end{array}$ \\
\hline $\mathrm{AUC}_{0-720}$ & $4261.3 \pm 146.8^{\mathrm{a}}$ & $\begin{array}{l}2650.0 \pm 211.1^{b} \\
(-36.9 \pm 6.6 \%)\end{array}$ & $\begin{array}{l}2024.9 \pm 209.0^{b} \\
(-51.9 \pm 5.3 \%)\end{array}$ \\
\hline$K_{10}$ & $0.0039 \pm 0.0002^{\mathrm{a}}$ & $\begin{array}{c}0.0028 \pm 0.0003^{b} \\
(-27.9 \pm 7.9 \%)\end{array}$ & $\begin{array}{c}0.0025 \pm 0.0002^{\mathrm{b}} \\
(-30.4 \pm 6.2 \%)\end{array}$ \\
\hline \multicolumn{4}{|l|}{ PHT-G } \\
\hline$C_{\max }$ & $1.7 \pm 0.2^{\mathrm{a}}$ & $\begin{array}{c}0.8 \pm 0.1^{\mathrm{b}} \\
(-51.7 \pm 4.2 \%)\end{array}$ & $\begin{array}{c}0.5 \pm 0.1^{\mathrm{b}} \\
(-65.1 \pm 10.4 \%)\end{array}$ \\
\hline $\mathrm{AUC}_{0-720}$ & $557.2 \pm 59.9^{a}$ & $\begin{array}{c}232.5 \pm 37.9^{\mathrm{b}} \\
(-51.7 \pm 12.1 \%)\end{array}$ & $\begin{array}{c}172.5 \pm 22.1^{\mathrm{b}} \\
(-64.8 \pm 8.5 \%)\end{array}$ \\
\hline$K_{10}$ & $0.0033 \pm 0.0003^{\mathrm{a}}$ & $\begin{array}{c}0.0019 \pm 0.0002^{b} \\
(-51.5 \pm 4.9 \%)\end{array}$ & $\begin{array}{c}0.0023 \pm 0.0003^{b} \\
(-39.9 \pm 7.3 \%)\end{array}$ \\
\hline \multicolumn{4}{|l|}{$\mathrm{HPPH}$} \\
\hline$C_{\max }$ & $4.5 \pm 0.3^{\mathrm{a}}$ & $\begin{array}{c}2.5 \pm 0.1^{\mathrm{b}} \\
(-43.9 \pm 4.6 \%)\end{array}$ & $\begin{array}{c}2.3 \pm 0.1^{\mathrm{b}} \\
(-46.3 \pm 6.9 \%)\end{array}$ \\
\hline $\mathrm{AUC}_{0-720}$ & $1556.0 \pm 81.5^{\mathrm{a}}$ & $\begin{array}{c}1058.3 \pm 45.1^{\mathrm{b}} \\
(-30.3 \pm 5.7 \%)\end{array}$ & $\begin{array}{c}954.0 \pm 49.8^{\mathrm{b}} \\
(-37.5 \pm 5.0 \%)\end{array}$ \\
\hline$K_{10}$ & $0.0013 \pm 0.0002^{\mathrm{a}}$ & $\begin{array}{l}0.0008 \pm 0.0003^{b} \\
(-67.9 \pm 13.8 \%)\end{array}$ & $\begin{array}{c}0.0003 \pm 0.0001^{\mathrm{b}} \\
(-76.6 \pm 7.0 \%)\end{array}$ \\
\hline \multicolumn{4}{|l|}{ HPPH-G } \\
\hline$C_{\max }$ & $14.8 \pm 0.7^{\mathrm{a}}$ & $\begin{array}{c}8.4 \pm 0.5^{\mathrm{b}} \\
(-42.5 \pm 4.0 \%)\end{array}$ & $\begin{array}{c}8.1 \pm 0.5^{\mathrm{b}} \\
(-44.3 \pm 4.2 \%)\end{array}$ \\
\hline $\mathrm{AUC}_{0-720}$ & $4482.9 \pm 114.7^{\mathrm{a}}$ & $\begin{array}{l}3430.8 \pm 208.5^{\mathrm{b}} \\
(-22.8 \pm 6.3 \%)\end{array}$ & $\begin{array}{l}3099.9 \pm 155.0^{\mathrm{b}} \\
(-30.6 \pm 3.7 \%)\end{array}$ \\
\hline$K_{10}$ & $0.0039 \pm 0.0002^{\mathrm{a}}$ & $\begin{array}{c}0.0018 \pm 0.0002^{\mathrm{b}} \\
(-53.6 \pm 3.9 \%)\end{array}$ & $\begin{array}{c}0.0016 \pm 0.0002^{\mathrm{b}} \\
(-59.3 \pm 4.7 \%)\end{array}$ \\
\hline
\end{tabular}

\footnotetext{
${ }_{\mathrm{a}, \mathrm{b}}$ Significant difference at $P<0.05$ denoted by different letters.

$C_{\max }(\mu \mathrm{g} / \mathrm{mL})$ : peak serum concentration.

$\mathrm{AUC}_{0-720}(\mu \mathrm{g} \cdot \mathrm{min} / \mathrm{mL})$ : areas under the curves from time zero to the last point.

$K_{10}$ : the elimination rate $\left(\mathrm{min}^{-1}\right)$.

Values are means $\pm \mathrm{SE}$.
}

were higher than those in MDCK II-MRP 2. In addition, the intracellular accumulations of PHT and HPPH were significantly increased by Indo in both cell lines.

In order to mimic the molecules interacting with MRP 2 in kidney, the RPMs of rats were prepared and characterized. HPLC analysis of RPMs showed that it contained 2.3, 13.0, 4.1 , and $2.0 \mu \mathrm{M}$ of glucuronides/sulfates of aloe-emodin, rhein, emodin, chrysophanol, respectively, and $6.4 \mu \mathrm{M}$ of rhein free form in the serum.

The effects of RPMs and Indo on the intracellular accumulation of PHT and HPPH in MDCK II-MRP 2 are shown in Figure 5. RPMs at 1-fold serum concentrations significantly increased the intracellular accumulation of PHT and $\mathrm{HPPH}$ by $51.7 \%$ and $46.7 \%$. As a positive control, Indo at $200 \mu \mathrm{M}$ significantly increased the intracellular accumulation of PHT and HPPH by $54.2 \%$ and $44.1 \%$, respectively.

\section{Discussions}

Owing to the general abundance of polyphenol glycosides in plants, characterization of the RP decoction used in this study was carried out to measure the concentrations of aloeemodin, rhein, emodin, chrysophanol, and physicon before and after acid hydrolysis. Quantitation results showed that upon acid hydrolysis the concentrations of aloe-emodin, 


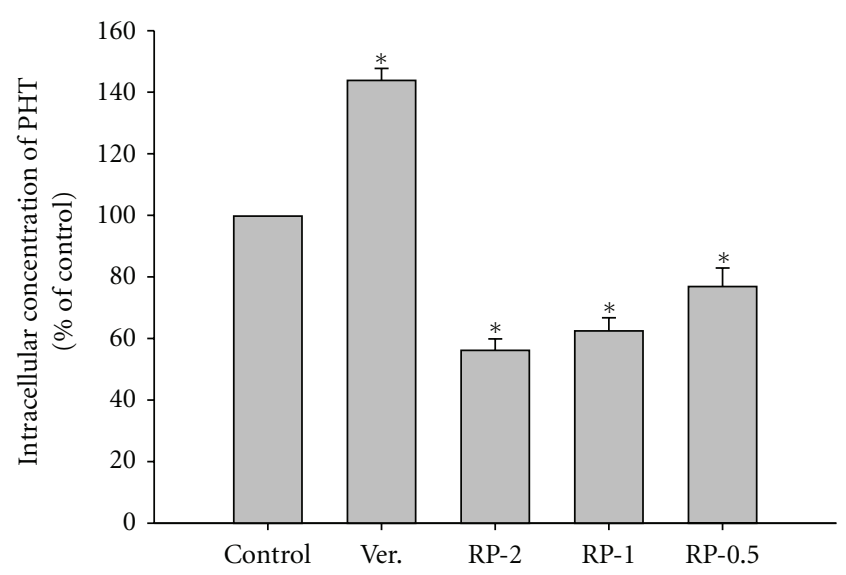

Figure 3: Effects of RP (2.0, 1.0 and $0.5 \mathrm{mg} / \mathrm{mL})$ and verapamil (Ver, $100 \mu \mathrm{M}$ as a positive control of P-gp inhibitor) on the accumulation of PHT in LS 180 cells. Data expressed as mean \pm S.D. of four determinations. ${ }^{*} P<0.05$.

rhein, emodin, chrysophanol, and physicon increased by $416 \%, 85 \%, 345 \%, 402 \%$ and $367 \%$, respectively, implying that the RP decoction contained aloe-emodin, emodin, chrysophanol, and physicon mainly in their glycoside form, whereas rhein was an exception existing more in the free form.

The assay methods of PHT and HPPH in serum and cell lysate were similar to a previously reported study but with some modifications made and they were validated in this study $[17,20]$. The determination of PHT-G and HPPH-G was performed indirectly through hydrolysis with $\beta$-glucuronidase [21]. Coadministration of single dose and pretreatment with the seven doses of RP all significantly decreased the AUC and $C_{\max }$ of PHT, PHT-G, HPPH, and HPPH-G, suggesting that RP decreased the oral bioavailability of PHT. The serum profiles revealed that the early exposure of PHT was markedly decreased, inferring that the absorption of PHT was hampered. This fact suggested that acute and chronic coadministrations of RP would result in diminished efficacy of PHT.

Based on previous studies which claimed that PHT was a substrate of P-gp and CYP 2C $[12,14]$, it is reasonable to assume that RP may induce $\mathrm{P}$-gp or CYP $2 \mathrm{C}$ thus resulting in the decreased absorption of PHT. However, the unaffected ratio of the AUC of HPPH plus HPPH-G to that of PHT plus PHT-G (data not shown) can be inferred that the decreased absorption of PHT cannot be attributed to the enhanced metabolism mediated by CYP 2C. Subsequently, the possible involvement of $\mathrm{P}$-gp in this interaction was investigated by using LS 180 cells to measure the effect of RP on the efflux transport of PHT. The result showed a decrease in intracellular accumulation of PHT in the presence of RP which indicated that the activity of P-gp could have been induced, which might explain the decreased absorption of PHT in rats. These results could also echo previous studies reporting that overexpression of P-gp could cause a decrease in PHT levels in the rats $[18,22]$.
While the rats were coadministered with RP in single dose or pretreated with seven doses, the significantly decreased $K_{10}$ of PHT, PHT-G, HPPH, and HPPH-G indicated that eliminations of both the parent form and the metabolites were inhibited in rats. It has been reported that majority of the dose of PHT was excreted as HPPH-G and only small amount was excreted as PHT-G in human urine $[23,24]$, thus it could be assumed that renal excretion of HPPH-G and PHT-G might also involve renal MRP 2 like PHT $[25,26]$. Therefore, it was suspected that RP might decrease the renal elimination of PHT, PHT-G, HPPH, and HPPH-G through the inhibition of MRP 2.

To explore the possible involvement of MRP 2 in this interaction, transport assays of PHT and HPPH in the presence and absence of Indo, an inhibitor of MRP 2, were conducted in MDCK II and MDCK II-MRP 2. The results showed that intracellular accumulation of PHT and HPPH was lower in MDCK II-MRP 2 than the MDCK II, thus suggesting that both PHT and HPPH were substrates of MRP 2. Moreover, the intracellular accumulations of PHT and HPPH in MDCK II-MRP 2 and MDCK II significantly increased by Indo had led to the confirmation that PHT and HPPH were substrates for MRP 2. To our knowledge, this is the first study reporting that HPPH is a substrate of MRP 2. Owing to the unavailability of PHT-G and HPPH-G, whether MRP 2 was involved in the efflux of PHT-G and HPPH-G could not be determined.

Our previous pharmacokinetic study of RP indicated that glucuronides/sulfates of aloe-emodin, rhein, emodin, and chrysophanol were the major molecules in the circulation, and rhein existed in part as free form $[3,8]$ which were putative substrates of MRPs. Therefore, the serum metabolites of RP (RPMs) were prepared and characterized for mimicking the molecules that interacted with MRP 2 in the kidney. A transport study was subsequently carried out using RPMs to measure the effect on the transport of PHT and HPPH in MDCK II-MRP 2. The increased accumulation of PHT and HPPH in MDCK II-MRP 2 indicated that the efflux activity of MRP 2 was inhibited by RPMs. It can be proposed that the $G / S$ of various anthraquinones and rhein free form in RPMs, existing as anions under $\mathrm{pH} 7.4$ and being putative substrates of MRP 2, are the causative agents that decreased the elimination rates of PHT, PHT-G, HPPH, and HPPH-G following coadministration of RP.

Although the elimination of PHT was inhibited by RPMs, the effect of decreasing the absorption of PHT caused by $\mathrm{RP}$ is much stronger than that on the elimination of PHT upon observing the serum profiles in Figure 2. Therefore, an overall effect of decreased systemic exposures to PHT, PHT-G, HPPH, and HPPH-G can be mainly attributable to a significant activation of P-gp by RP. Therefore, it is predicted that the combined therapy of RP with any western medicines which are P-gp substrates, such as digoxin and cyclosporine, can result in diminished efficacy. On the contrary, if RP is coadministered with any western medicines which are MRP 2 substrates rather than P-gp substrates, the efficacy or toxicity might be increased.

In conclusion, acute and chronic coadministration of RP can significantly decrease the systemic exposure of PHT, 


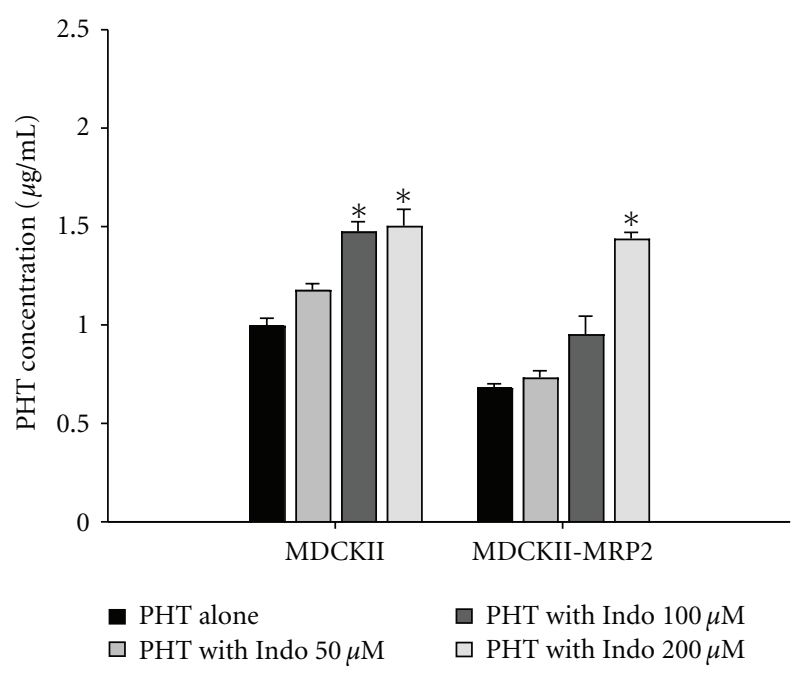

(a)

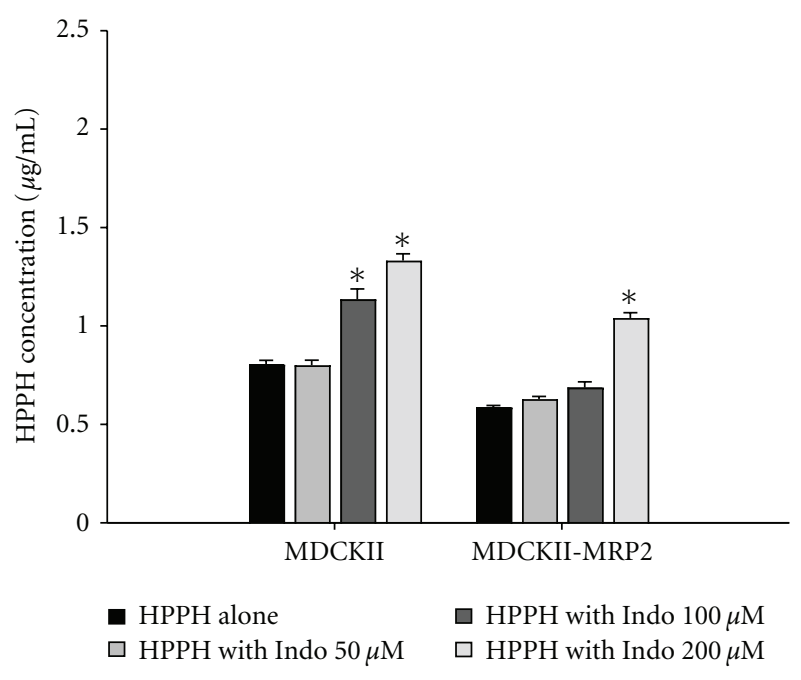

(b)

FIGURE 4: Effects of indomethacin (Indo) on the intracellular accumulation of PHT ((a), $10 \mu \mathrm{M})$ and HPPH ((b), $10 \mu \mathrm{M})$ in MDCKII and MDCKII-MRP 2 cells. Data expressed as mean \pm S.D. of four determinations. ${ }^{*} P<0.05$.

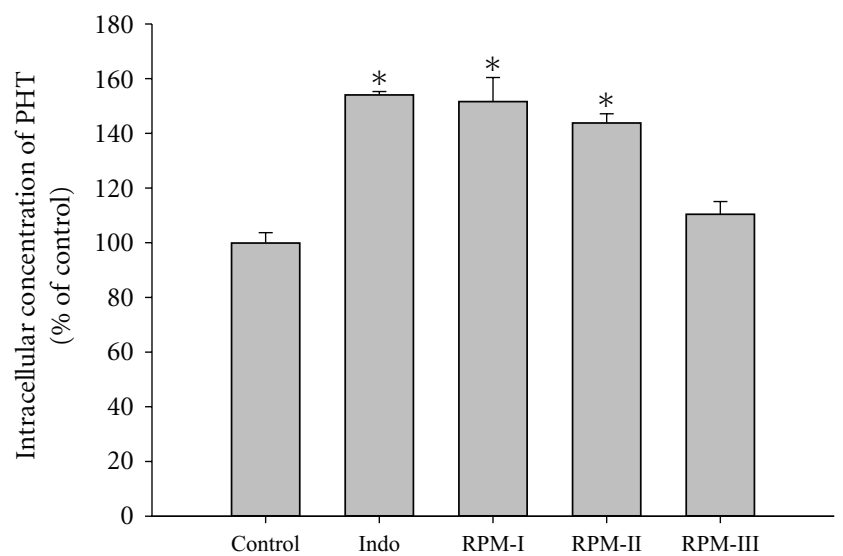

(a)

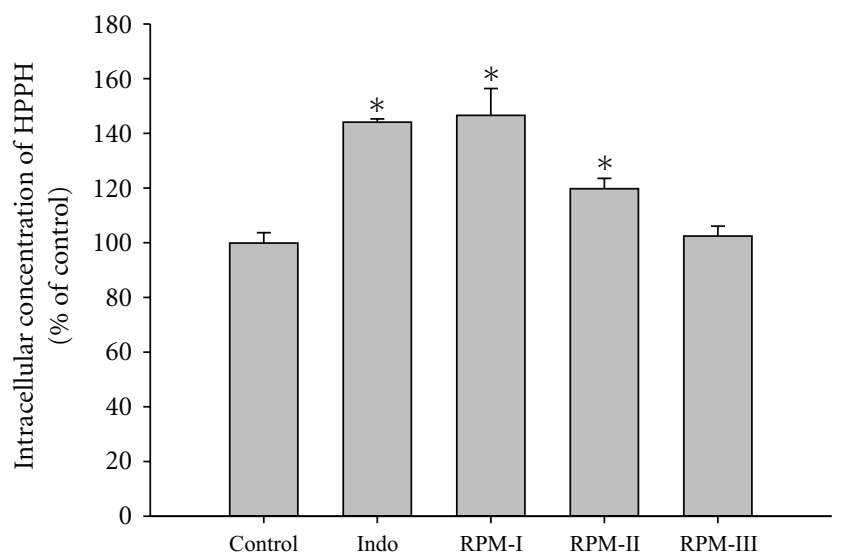

(b)

FIGURE 5: Effects of RP metabolites (RPMs) and indomethacin (Indo, $200 \mu \mathrm{M}$ as a positive control of MRP 2 inhibitor) on the accumulation of PHT (a) and HPPH (b) in MDCKII-MRP2 cells. Data expressed as mean \pm S.D. of five determinations. ${ }^{*} P<0.05$. RPMs-I, II, III: $1.0-$, 0.5 -, and 0.25 -fold serum concentration, respectively (1.0-fold: containing $2.3 \mu \mathrm{M}$ of aloe emodin G/S, $6.4 \mu \mathrm{M}$ of rhein, $13.0 \mu \mathrm{M}$ of rhein $\mathrm{G} / \mathrm{S}, 4.1 \mu \mathrm{M}$ of emodin $\mathrm{G} / \mathrm{S}$, and $2.0 \mu \mathrm{M}$ of chrysophanol G/S).

PHT-G, HPPH, and HPPH-G in rats mainly through activation of P-gp. Therefore, the results from this investigation conclude that caution will need to be exercised when RP and PHT are used concurrently.

\section{Acknowledgments}

The work was in part supported by National Science Council, Taiwan, (NSC 99-2320-B-039-017-MY3, NSC99-2628B-039-005-MY3) and China Medical University, Taichung, Taiwan, (CMU100-S-17, CMU100-S-05).

\section{References}

[1] M. F. Clifford, Ed., Rhubarb: The Wondrous Drug, Princeton University Press, Princeton, NJ, USA, 1992.
[2] J. Han, M. Ye, M. Xu et al., "Comparison of phenolic compounds of rhubarbs in the section deserticola with Rheum palmatum by HPLC-DAD-ESI-MSn," Planta Medica, vol. 74, no. 8, pp. 873-879, 2008.

[3] C. S. Shia, S. Y. Tsai, J. C. Lin et al., "Steady-state pharmacokinetics and tissue distribution of anthraquinones of Rhei Rhizoma in rats," Journal of Ethnopharmacology, vol. 137, no. 3, pp. 1388-1394, 2011.

[4] J. W. Gu, H. Hasuo, M. Takeya, and T. Akasu, "Effects of emodin on synaptic transmission in rat hippocampal CA1 pyramidal neurons in vitro," Neuropharmacology, vol. 49, no. 1, pp. 103-111, 2005.

[5] C. Y. Li, Y. C. Hou, P. D. Lee Chao, C. S. Shia, I. C. Hsu, and S. H. Fang, "Potential ex vivo immunomodulatory effects of San-Huang-Xie-Xin-Tang and its component herbs on mice and humans," Journal of Ethnopharmacology, vol. 127, no. 2, pp. 292-298, 2010. 
[6] C. Y. Chang, H. L. Chan, H. Y. Lin et al., "Rhein induces apoptosis in human breast cancer cells," Evidence-Based Complementary and Alternative Medicine, vol. 2012, Article ID 952504, 8 pages, 2012.

[7] Y. C. Chang, T. Y. Lai, C. S. Yu et al., "Emodin induces apoptotic death in murine myelomonocytic leukemia WEHI-3 cells in vitro and enhances phagocytosis in leukemia mice in vivo," Evidence-Based Complementary and Alternative Medicine, vol. 2011, Article ID 523596, 13 pages, 2011.

[8] C. S. Shia, S. H. Juang, S. Y. Tsai et al., "Metabolism and pharmacokinetics of anthraquinones in rheum palmatum in rats and ex vivo antioxidant activity," Planta Medica, vol. 75, no. 13, pp. 1386-1392, 2009.

[9] A. Odani, Y. Hashimoto, Y. Otsuki et al., "Genetic polymorphism of the CYP2C subfamily and its effect on the pharmacokinetics of phenytoin in Japanese patients with epilepsy," Clinical Pharmacology and Therapeutics, vol. 62, no. 3, pp. 287-292, 1997.

[10] M. A. Falconer and S. Davidson, "Coarse features in epilepsy as a consequence of anticonvulsant therapy. Report of cases in two pairs of identical twins," The Lancet, vol. 2, no. 7838, pp. 1112-1114, 1973.

[11] E. B. Lefebvre, R. G. Haining, and R. F. Labbé, "Coarse facies, calvarial thickening and hyperphosphatasia associated with long-term anticonvulsant therapy," New England Journal of Medicine, vol. 286, no. 24, pp. 1301-1302, 1972.

[12] H. Potschka and W. Löscher, "In vivo evidence for Pglycoprotein-mediated transport of phenytoin at the bloodbrain barrier of rats," Epilepsia, vol. 42, no. 10, pp. 1231-1240, 2001.

[13] H. Potschka, M. Fedrowitz, and W. Löscher, "Multidrug resistance protein MRP2 contributes to blood-brain barrier function and restricts antiepileptic drug activity," Journal of Pharmacology and Experimental Therapeutics, vol. 306, no. 1, pp. 124-131, 2003.

[14] M. Bajpai, L. K. Roskos, D. D. Shen, and R. H. Levy, "Roles of cytochrome P4502C9 and cytochrome P4502C19 in the stereoselective metabolism of phenytoin to its major metabolite," Drug Metabolism and Disposition, vol. 24, no. 12, pp. 14011403, 1996.

[15] T. Yasumori, L. S. Chen, Q. H. Li et al., "Human CYP2Cmediated stereoselective phenytoin hydroxylation in Japanese: difference in chiral preference of CYP2C9 and CYP2C19," Biochemical Pharmacology, vol. 57, no. 11, pp. 1297-1303, 1999.

[16] M. Nakajima, N. Sakata, N. Ohashi, T. Kume, and T. Yokoi, "Involvement of multiple UDP-glucuronosyltransferase 1A isoforms in glucuronidation of 5-(4'-hydroxyphenyl)-5-phenylhydantoin in human liver microsomes," Drug Metabolism and Disposition, vol. 30, no. 11, pp. 1250-1256, 2002.

[17] H. Yamanaka, M. Nakajima, Y. Hara et al., "Urinary excretion of phenytoin metabolites, 5-(4'-hydroxyphenyl)-5-phenylhydantoin and its O-glucuronide in humans and analysis of genetic polymorphisms of UDP-glucuronosyltransferases," Drug Metabolism and Pharmacokinetics, vol. 20, no. 2, pp. 135143, 2005.

[18] E. A. van Vliet, R. van Schaik, P. M. Edelbroek et al., "Regionspecific overexpression of P-glycoprotein at the blood-brain barrier affects brain uptake of phenytoin in epileptic rats," Journal of Pharmacology and Experimental Therapeutics, vol. 322, no. 1, pp. 141-147, 2007.

[19] M. M. Bradford, "A rapid and sensitive method for the quantitation of microgram quantities of protein utilizing the principle of protein dye binding," Analytical Biochemistry, vol. 72, no. 1-2, pp. 248-254, 1976.

[20] Y. Caraco, M. Muszkat, and A. J. Wood, "Phenytoin metabolic ratio: a putative marker of CYP2C9 activity in vivo," Pharmacogenetics, vol. 11, no. 7, pp. 587-596, 2001.

[21] T. Aliwarga, J. C. Cloyd, V. Goel et al., "Excretion of the principal urinary metabolites of phenytoin and absolute oral bioavailability determined by use of a stable isotope in patients with epilepsy," Therapeutic Drug Monitoring, vol. 33, no. 1, pp. 56-63, 2011.

[22] J. P. Bankstahl and W. Löscher, "Resistance to antiepileptic drugs and expression of P-glycoprotein in two rat models of status epilepticus," Epilepsy Research, vol. 82, no. 1, pp. 70-85, 2008.

[23] E. W. Maynert, "The metabolic fate of diphenylhydantoin in the dog, rat and man," The Journal of Pharmacology and Experimental Therapeutics, vol. 130, pp. 275-284, 1960.

[24] R. G. Smith, G. D. Daves Jr., R. K. Lynn, and N. Gerber, "Hydantoin ring glucuronidation: characterization of a new metabolite of 5,5-diphenylhydantoin in man and the rat," Biomedical Mass Spectrometry, vol. 4, no. 4, pp. 275-279, 1977.

[25] G. Jedlitschky, U. Hoffmann, and H. K. Kroemer, "Structure and function of the MRP2 (ABCC2) protein and its role in drug disposition," Expert Opinion on Drug Metabolism and Toxicology, vol. 2, no. 3, pp. 351-366, 2006.

[26] A. C. Auansakul and M. Vore, "The effect of pregnancy and estradiol-17 $\beta$ treatment on the biliary transport maximum of dibromosulfophthalein, and the glucuronide conjugates of 5-phenyl-5-p-hydroxyphenyl[14C]hydantoin and [14C] morphine in the isolated perfused rat liver," Drug Metabolism and Disposition, vol. 10, no. 4, pp. 344-349, 1982. 


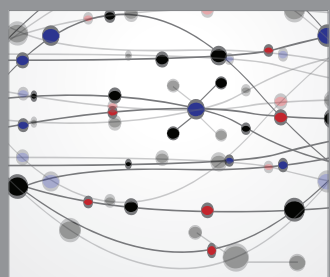

The Scientific World Journal
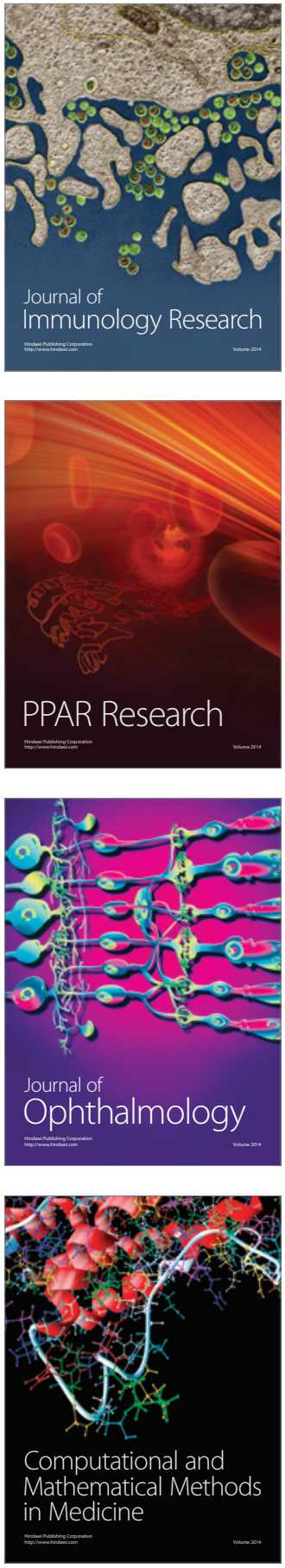

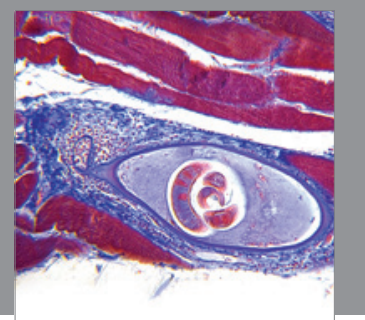

Gastroenterology

Research and Practice
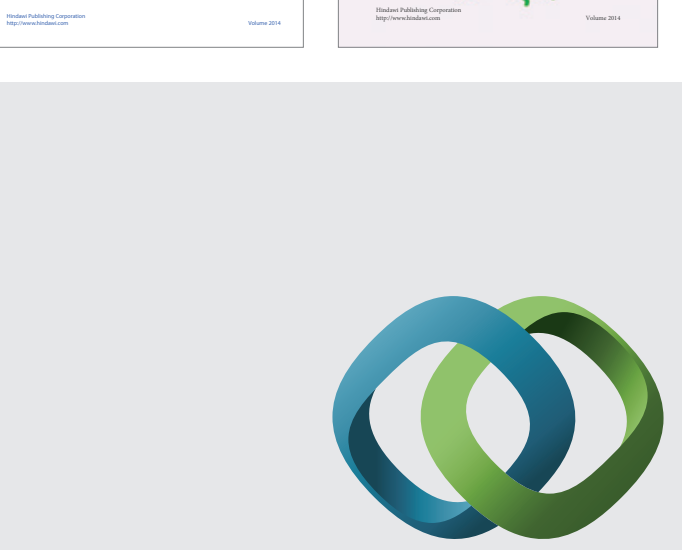

\section{Hindawi}

Submit your manuscripts at

http://www.hindawi.com
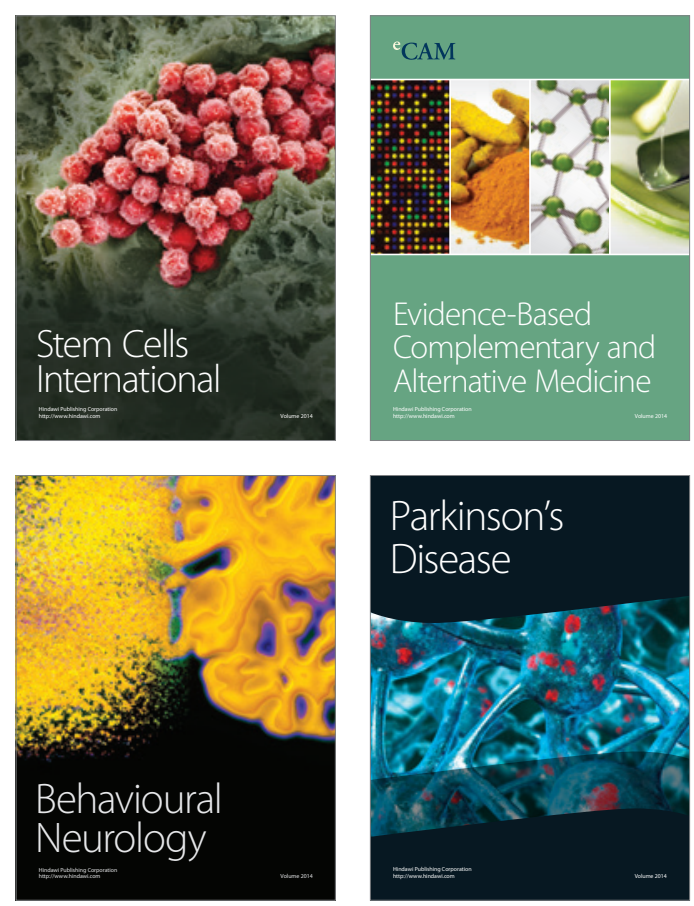

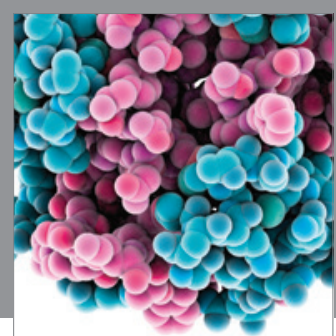

Journal of
Diabetes Research

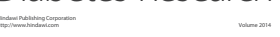

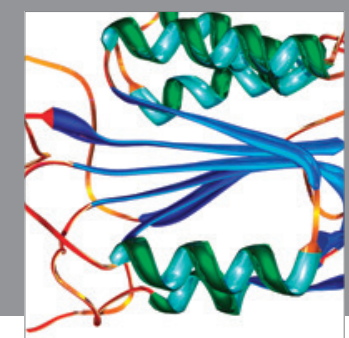

Disease Markers
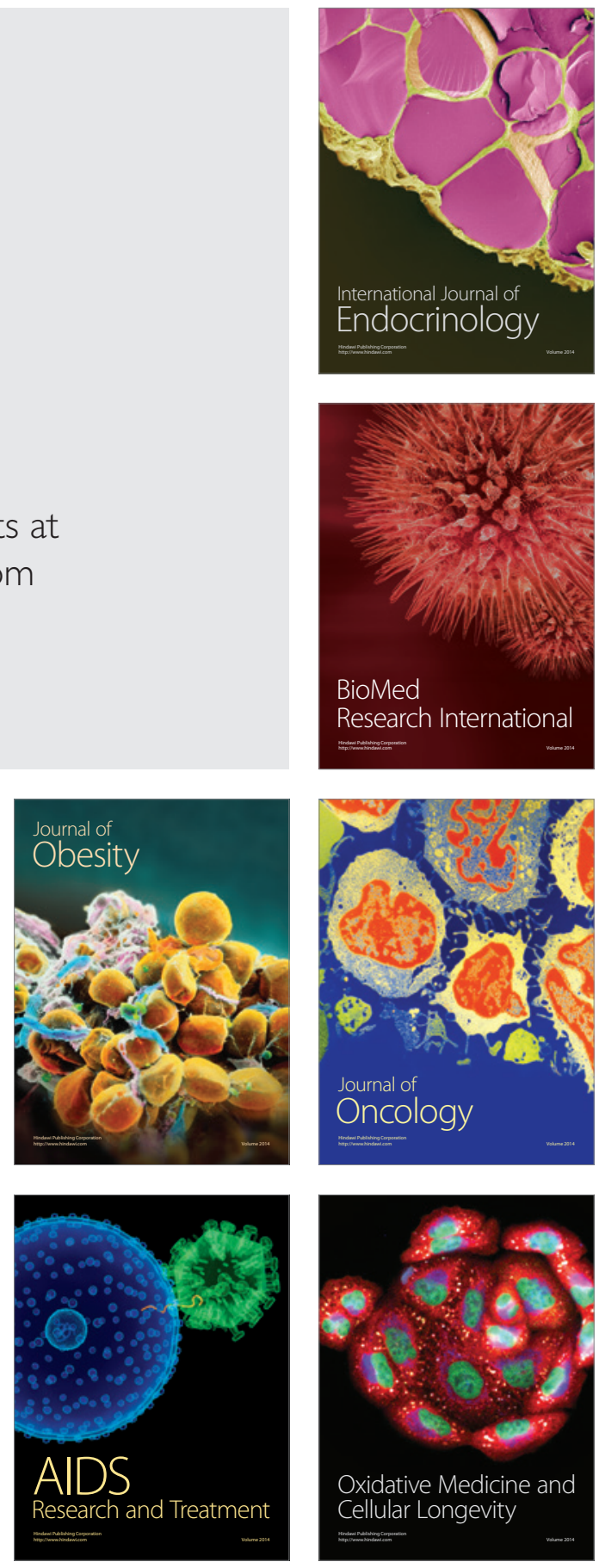